\title{
Does the Great Recession Contribute to the Convergence of Health Care Expenditures in the US States?
}

\author{
Jesús Clemente ${ }^{1} \mathbb{D}$, Angelina Lázaro-Alquézar ${ }^{2}$ and Antonio Montañés ${ }^{1, *(\mathbb{D})}$ \\ 1 Department of Economic Analysis, University of Zaragoza, 50005 Zaragoza, Spain; clemente@unizar.es \\ 2 Department of Applied Economics, University of Zaragoza, 50005 Zaragoza, Spain; alazaro@unizar.es \\ * Correspondence: amontane@unizar.es; Tel.: +34-976-762221
}

Received: 30 November 2019; Accepted: 11 January 2020; Published: 15 January 2020

check for updates

\begin{abstract}
This paper examines whether the Great Recession has altered the disparities of the US regional health care expenditures. We test the null hypothesis of convergence for the US real per capita health expenditure for the period 1980-2014. Our results indicate that the null hypothesis of convergence is clearly rejected for the total sample as well as for the pre-Great Recession period. Thus, no changes are found in this regard. However, we find that the Great Recession has modified the composition of the estimated convergence clubs, offering a much more concentrated picture in 2014 than in 2008, with most of the states included in a big club, and only 5 (Nevada, Utah, Arizona, Colorado and Georgia) exhibiting a different pattern of behavior. These two estimated clubs diverge and, consequently, the disparities in the regional health sector have increased.
\end{abstract}

Keywords: great recession; health care expenditures; long-term; convergence analysis; Phillips-Sul

\section{Introduction}

Economists agree that the Great Recession has been one of the deepest and most extensive economic downturns in recent history. The health sector did not escape this effect and suffered an immediate and long-lasting impact. If we focus on the case of the USA, Martin el al. [1,2] show that US National health spending grew by $4.6 \%$ in 2008 and 3.9\% in 2009. After 2009, the growth rates of health spending remained below $4 \%$ for five consecutive years, with the remarkable minimum of $2.9 \%$ in 2013 . This behavior meant that the health expenditure share over GDP remained unchanged until 2014.

This decline in US health spending has been quite heterogeneous. If we analyze the Personal Health Care Expenditure (PHCE) data for 2009-2014, we observe that it grew by 6.7\% in North Dakota and by $2.5 \%$, the lowest, in Rhode Island. If we further take into account that California's PHCE is $11.5 \%$ of US total, whereas the contribution of Wyoming is just $0.2 \%$, we can understand that US health spending is heterogeneous across US States.

Some recent papers have analyzed these disparities, putting special emphasis on the convergence of the US regional health expenditure. For instance, Cuckler et al. [3] and, more recently, Apergis et al. [4] and Clemente et al. [5], study convergence with State of Residence health data. Similarly, Wang [6] and Panopoulou and Pantelidis [7] consider State of Provider health data. The results obtained by these authors are mixed, although evidence of convergence is scarce. Other interesting works related with this issue are the ones of Caporale et al. [8] and Zezza [9]. However, none of these previous papers deal directly with the possible effect of the Great Recession on convergence.

Against this background, the aim of this paper is to analyze whether the Great Recession has affected the disparities in US regional health care expenditures. We focus on State of Provider health data and our sample covers 1980-2014. Therefore, our results can be understood as an extension of those of Panopoulu and Pantelidis [7] for the post-Great Recession period. 
The structure of the paper is as follows. Section 2 describes the data and introduces the methodology. Section 3 presents and discusses the empirical results. Section 4 offers some concluding remarks.

\section{Materials and Methods}

The annual data of Personal Health Care from 1980 to 2014 have been obtained from the Center of Medicare and Medicaid Services (CMS) for the 50 US states plus the ones of the District of Columbia. Unlike Clemente et al. [5], this variable is measured by State of Provider. We have transformed the data into real per capita terms by using the population of each state and the US consumer price index, the data for which have been obtained from the US Bureau of Economic Analysis.

To analyze the disparities in US regional health expenditures, we apply the methodology of Phillips and Sul $[10,11]$. They develop a procedure that allows, first, to test the total convergence hypothesis and, if this hypothesis is rejected, to subsequently estimate the number of different convergence clubs. Details of this methodology are presented in a separate Appendix A.

\section{Results and Discussion}

The results of Table 1 show that the null hypothesis of convergence is clearly rejected for PHCE for 1980-2007 and for the total sample (1980-2014). So, nothing has changed from this perspective. However, we should note that the estimation of the parameter that measures the speed of convergence has augmented in absolute terms, going from -0.58 to -0.78 . Similarly, the statistic for testing the null hypothesis of convergence goes from -45.2 to -66.0 . Thus, greater heterogeneity is found after the Great Recession.

Table 1. Testing for convergence.

\begin{tabular}{|c|c|c|}
\hline & 1980-2007 & 1980-2014 \\
\hline \multicolumn{3}{|c|}{ Panel I. Phillips-Sul test } \\
\hline Personal Health Care & $-0.58(-45.2)$ & $-0.78(-66.0)$ \\
\hline \multicolumn{3}{|c|}{ Panel II. Estimated Convergence clubs } \\
\hline Club 1 & $\begin{array}{c}\text { AK, CT, DE, DC, IN, IA, KS, KY, ME, } \\
\text { MD, MA, MN, MS, MT, NE, NH, NJ, } \\
\text { NY, NC, ND, OH, PA, RI, SC, SD, TN, } \\
\text { VT, WV, WI, WY }\end{array}$ & $\begin{array}{l}\text { AL, AK, AR, CA, CT, DE, DC, FL, HI, } \\
\text { ID, IL, IN, IA, KS, KY, LA, ME, MD, MA, } \\
\text { MI, MN, MS, MO, MT, NE, NH, NJ, NM, } \\
\text { NY, NC, ND, OH, OK, OR, PA, RI, SC, } \\
\text { SD, TN, TX, VT, VA, WA, WV, WI, WY }\end{array}$ \\
\hline Club 2 & $\begin{array}{c}\text { AL, AZ, AR, CA, CO, FL, GA, HI, ID, } \\
\text { IL, LA, MI, MO, NV, NM, OK, OR, TX, } \\
\text { UT, VA, WA }\end{array}$ & $\mathrm{AZ}, \mathrm{CO}, \mathrm{GA}, \mathrm{NV}, \mathrm{UT}$ \\
\hline
\end{tabular}

This table reports the results of the PS methodology for testing the null hypothesis of convergence. The different cells of Panel I present the value of the estimator of the log-t parameter and, below it, in parentheses, the PS statistic. The distribution of this statistic asymptotically converges towards a standard $N(0,1)$ distribution. So, we should use the -1.65 one-side critical value to reject the null hypothesis of convergence. Panel II includes the estimated convergence clubs, which have been obtained using the clustering algorithm designed in Phillips and Sul [10]. In all the cases, the Hodrick-Prescott filter has been employed, with the smoothing parameter being equal to 400 . The different states are represented by their corresponding two-letter postal abbreviations.

Next, we analyze the existence of convergence clubs in the US States. The results are presented in Panel II of Table 1 and mapped in Figure 1. As can be seen, we have estimated two clubs. Club 1 includes the states with the largest PHCE while Club 2 includes the states with the lowest levels of PHCE. The states in Club 2 for the total sample are AZ, CO, GA, NV and UT, clearly fewer than those in Club 2 for the pre-Great Recession sample (21 states). 


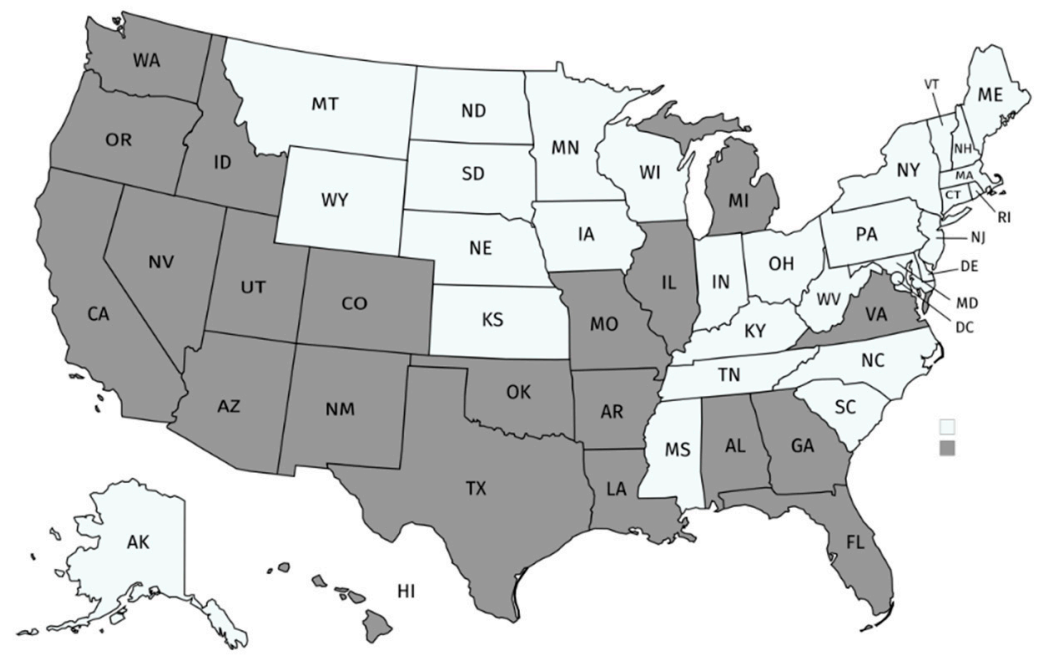

Sample 1980-2007

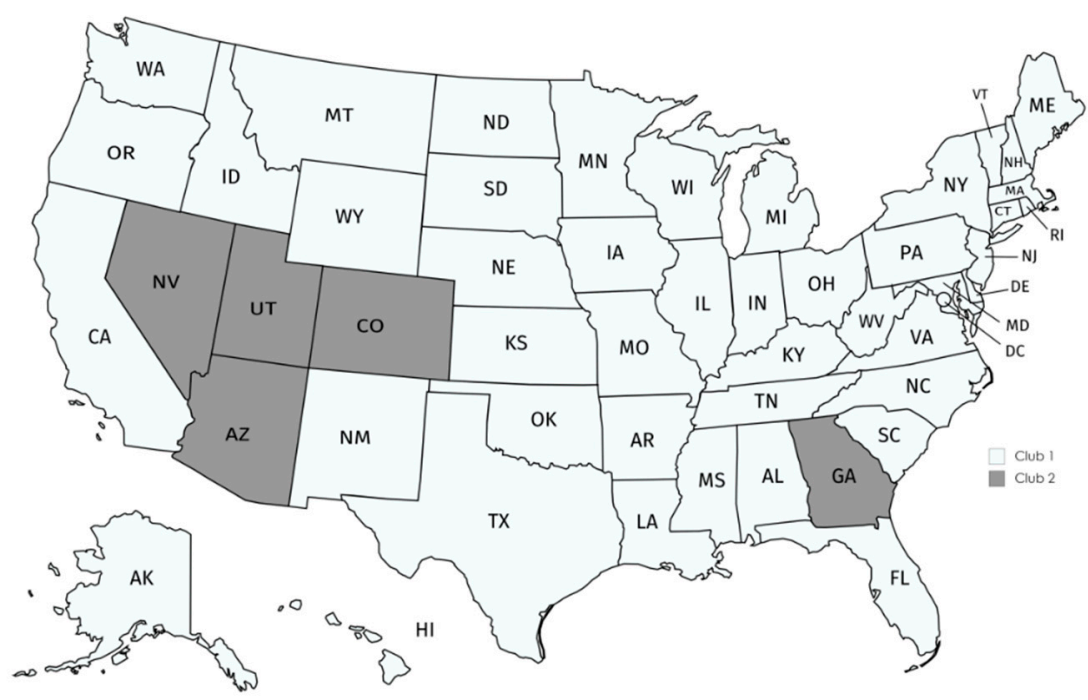

Sample 1980-2014

Figure 1. Estimated clubs for real per capita Personal Health Care Expenditure.

To study whether the differences in the composition of the clubs are statistically relevant, we have employed the Mann-Whitney-Wilcoxon, Kruskal-Wallis and van der Waarden non-parametric statistics. Their respective values are 3.61, 13.09, and 13.63, rejecting the null hypothesis of the median equity when the results of the pre-Great Recession and total sample are compared. Therefore, our results provide robust evidence against the hypothesis that the estimated convergence clubs are similar for both the pre- and the post-crisis samples. Thus, it can be concluded that the Great Recession has statistically changed the pattern of behavior of health expenditure in the US.

To appreciate the changes caused by the Great Recession, Figure 2 shows the average values of PHCE for the states in club 1 and club 2 when the total sample is considered. We can observe that their growth rates diminished after 2008. However, the states in Club 2 did so more intensively than those in Club 1. Therefore, the distance between the two clubs has augmented in the 2008-2014 period, increasing the divergence between them. 


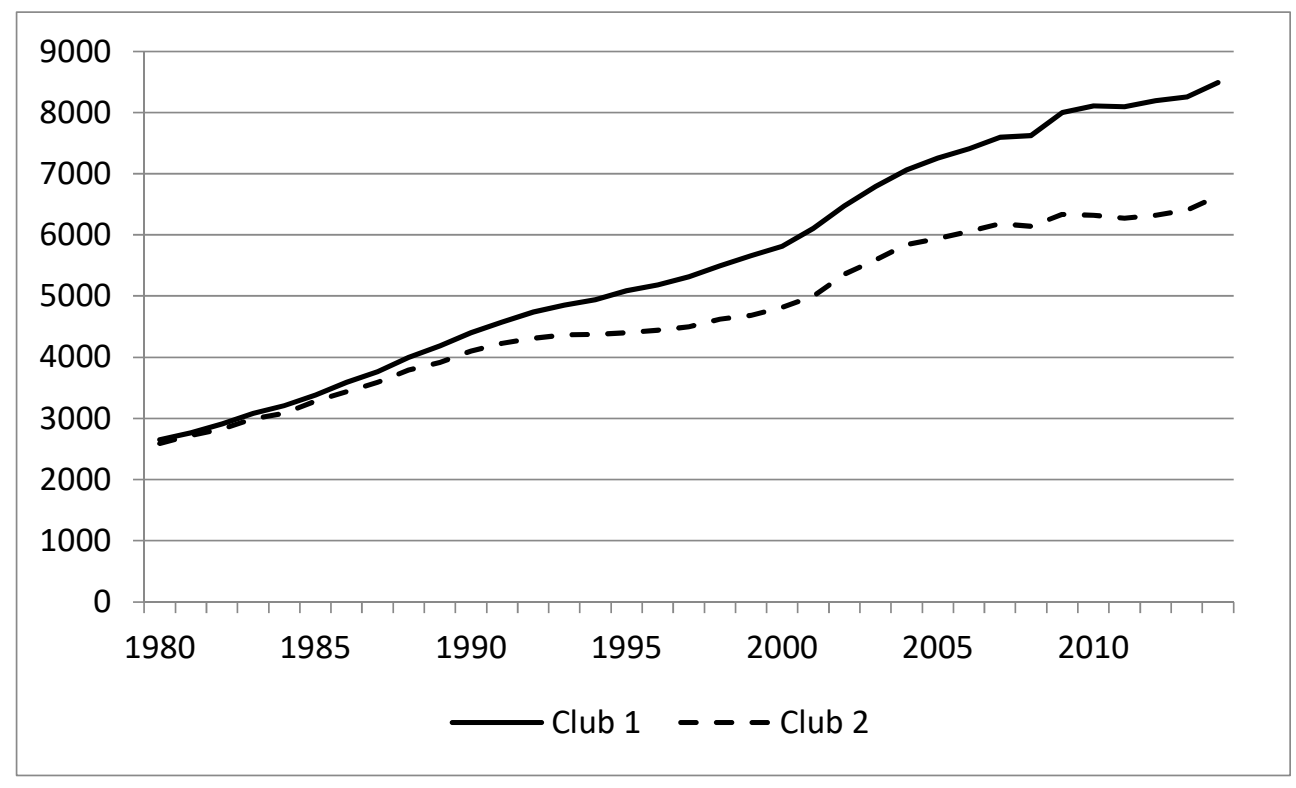

Evolution of PHCE

Figure 2. Average values of the PHCE of the states in Club 1 and Club 2 when the 1980-2014 sample is considered.

The estimated clubs presented in this paper are similar to those of Clemente et al. [7], where state-of-residence data is employed, although the final dimension of our Club 2 is clearly lower and, therefore, the effect of the Great Recession is more intensely observed. Finally, we should note that the analysis of the forces that drive the creation of the clubs should offer similar results and to the one carried out in the previously mentioned work, where the per capita GDP plays a crucial role.

\section{Conclusions}

The Great Recession has had an important impact on most sectors of the US economy, especially in health care expenditure given its dependence of the evolution of the economy. As PHCE varies considerably across states, we have analyzed whether the economic crisis has affected the convergence of health expenditure in the US states. Our empirical results reject the null hypothesis of convergence for the two samples considered. We have also found that the estimated convergence clubs have been affected by the Great Recession because the composition of the estimated clubs for the total sample is different to that of the pre-Great Recession sample. In particular, we can observe the creation of a "big club", which includes most of the States, with only five states (Nevada, Utah, Arizona, Colorado and Georgia) in Club 2. There exists a growing gap between these two clubs, although we can appreciate a slight reduction of this divergent process in the last two years of the sample. Thus, it seems that the recovery of the economy may help to reduce the distance between the health expenditures of the two estimated clubs, though this would require further analysis when new data are available.

Finally, given that the relationship between health care spending and the quality of care is a fundamental part of understanding geographic variations, our quantitative analysis of expenditure should be complemented with a study of the efficiency of the US health system. Then, it would be interesting to extend our study to include the analysis of health outcomes (infant mortality rate or life expectancy, for instance. Similarly, and as Nghiem and Connelly [12] do for the OECD countries, the analysis of the determinants of the health care expenditures could provide additional insights. However, we have preferred to leave both analyses for future studies given that they require more complex analysis than the ones presented in this note. 
Author Contributions: The co-authors had together contributed to the completion of this article. Specifically, it follows their individual contribution: Conceptualization, J.C., A.L.-A. and A.M.; Methodology, J.C., A.L.-A. and A.M.; Formal analysis, J.C., A.L.-A. and A.M.; Writing-Original draft preparation, A.L.-A. and A.M.; Writing-Review and editing, J.C., A.L.-A. and A.M. All authors have read and agreed to the published version of the manuscript.

Funding: This research was funded by MEC, grant number ECO2015-65967-R and by Aragonese Government, project LMP71_18.

Acknowledgments: The paper has benefited from the comments of two anonymous referees.

Conflicts of Interest: The authors declare no conflict of interest.

\section{Appendix A}

In order to test for the null hypothesis of convergence, we follow the recent papers of Phillips and Sul $[10,11]$ (PS, hereafter) where they develop a framework that allows us to test for the convergence hypothesis and then, if this hypothesis is rejected, to estimate the convergence clubs that group the child mortality rate behavior. The PS methodology is closely related to the standard sigma-convergence analysis, a concept introduced by Barro and Sala-i-Martin $[13,14]$, in that it tests for the decline of the variable of interest over time in the cross-sectional dispersion. However, it clearly outperforms the classical convergence analysis, namely, the abovementioned sigma-convergence concept and the beta-convergence concept, which was first introduced by Baumol [15]. The PS methodology is based on a general nonlinear time-varying factor model, which admits the presence of transitional heterogeneity. Additionally, it is flexible with respect to the time properties of the variables under analysis because it does not impose any particular assumption about them. Finally, it is clearly free of the criticism received by the beta-convergence analysis in De Long [16] and Quah [17]. As a consequence, the use of this methodology has recently become very popular in convergence analysis, including some applications for the case of health variables as we can see in Clemente et al [5], Panopupoulou and Pantelidis [7] and Nghiem and Connelly [12].

Following these authors, let us consider that $X_{i t}$ represents the US regional per capita health care expenditure, with $I=1,2, \ldots, 51$ (the 50 US states plus the District of Columbia) and $t=1970, \ldots, 2014$. This variable can be decomposed as $X_{i t}=\delta_{i t} \mu_{t}$, where $\mu_{t}$ and $\delta_{i t}$ are the common and the idiosyncratic components, respectively. PS suggest testing for convergence by analyzing whether $\delta_{\text {it }}$ converges towards $\delta$. To do so, they first define the relative transition component:

$$
h_{i t}=\frac{X_{i t}}{N^{-1} \sum_{i=1}^{N} X_{i t}}=\frac{\delta_{i t}}{N^{-1} \sum_{i=1}^{N} \delta_{i t}}
$$

In the presence of convergence, $\mathrm{h}_{\mathrm{it}}$ should converge towards unity, while its cross-sectional variation, $\mathrm{H}_{\mathrm{it}}$, is defined as follows:

$$
H_{i t}=N^{-1} \sum_{i=1}^{N}\left(h_{i t}-1\right)^{2} \stackrel{A s}{\rightarrow} 0, \text { as } T \stackrel{\text { as }}{\rightarrow} \infty
$$

and should go to 0 when $\mathrm{T}$ goes towards infinity. Then, PS test for convergence by estimating the following equation:

$$
\log \frac{H_{1}}{H_{t}}-2 \log [\log (t)]=\alpha+\beta \log (t)+u_{t}, t=T_{0}, \ldots, T
$$

with $T_{o}=[r T]$, and $r=0.3$, as suggested by PS. Equation (A3) is commonly known as the log-t regression. The null hypothesis of convergence is rejected whenever parameter $\beta$ is lower than 0 . PS suggest estimating model (A3) by methods which correct for the presence of autocorrelation and heteroskedasticity and, later, employ the $t$-statistic to test the null hypothesis $\beta=0$. The use of these robust methods ensures that this t-ratio converges towards a standard $\mathrm{N}(0,1)$ distribution and, therefore, 
we will reject the null hypothesis of convergence whenever this t-statistic takes values lower than -1.65 .

If we reject convergence, PS propose the following robust clustering algorithm for identifying clubs in a panel:

i. Order the $\mathrm{N}$ states according to their final values

ii. Starting from the highest-order state, add adjacent states from our ordered list and estimate model (A3). Then, select the core group by maximizing the value of the convergence $t$-statistic, subject to the restriction that it is greater than -1.65 .

iii. Continue adding one state at a time of the remaining states to the core group, and re-estimate model (A3) for each formation. Use the sign criterion ( $t$-statistic $>0$ ) to decide whether a state should join the core group.

iv. For the remaining states, repeat steps ii-iii iteratively and stop when clubs can no longer be formed. If the last group does not have a convergence pattern, conclude that its members diverge.

PS recommend performing club merging tests after running the algorithm using Equation (A3) in order to avoid the over-estimation of the number of clubs.

Finally, we have followed the suggestion of PS and we have extracted the trend components of the series by filtering them using the Hodrick and Prescott [18] filter, applying the standard value $\lambda=400$.

The results that we have obtained are presented in Table 1.

\section{References}

1. Martin, A.; Lassman, D.; Whittle, L.; Catlin, A.; The National Health Expenditure Accounts Team. Recession Contributes to Slowest Annual Rate of Increase in Health Spending in Five Decades. Health Aff. 2011, 30, 11-12. [CrossRef] [PubMed]

2. Martin, A.; Lassman, D.; Whittle, L.; Catlin, A.; The National Health Expenditure Accounts Team. National Health Spending in 2014: Faster Growth Driven by Coverage Expansion and Prescription Drug Spending. Health Aff. 2016, 35, 150-160. [CrossRef] [PubMed]

3. Cuckler, G.; Martin, A.; Whittle, L.; Heffler, S.; Sisko, A.; Lassman, D.; Benson, J. Health Spending by State of Residence, 1991-2009. Medicare Medicaid Res. Rev. 2011, 1, E1-E31. [CrossRef] [PubMed]

4. Apergis, N.; Chang, T.; Christou, C.; Gupta, R. Convergence of health care expenditures across the US States: A reconsideration. Soc. Indic. Res. 2017, 133, 303-316. [CrossRef]

5. Clemente, J.; Lázaro-Alquézar, A.; Montañés, A. US State health expenditure convergence: A revisited analysis. Econ. Model. 2019, 83, 210-220. [CrossRef]

6. Wang, Z. The Convergence of Health Care Expenditures in the US States. Health Econ. 2009, 18, 55-70. [CrossRef] [PubMed]

7. Panopoulou, E.; Pantelidis, T. Cross-state disparities in us health care expenditures. Health Econ. 2013, 22, 451-465. [CrossRef] [PubMed]

8. Caporale, G.M.; Cunado, J.; Gil-Alana, L.A.; Gupta, R. The relationship between healthcare expenditure and disposable personal income in the US states: A fractional integration and cointegration analysis. Empir. Econ. 2018, 55, 913-935. [CrossRef]

9. Zezza, M.A. Convergence in health care spending across counties in New York from 2007 through 2016. PLoS ONE 2019, 14, e0215850. [CrossRef] [PubMed]

10. Phillips, P.C.B.; Sul, D. Transition modelling and econometric convergence tests. Econometrica 2007, 756, 1771-1855. [CrossRef]

11. Phillips, P.C.B.; Sul, D. Economic transition and growth. J. Appl. Econom. 2009, 247, 1153-1185. [CrossRef]

12. Nghiem, S.H.; Connelly, L.B. Convergence and determinants of health expenditures in OECD countries. Health Econ. Rev. 2017, 7, 29. [CrossRef] [PubMed]

13. Barro, R.; Sala-i-Martin, X. Convergence across states and regions. Brook. Pap. Econ. Act. 1991,1,107-158. [CrossRef]

14. Barro, R.; Sala-i-Martin, X. Convergence. J. Political Econ. 1992, 100, 223-251. [CrossRef] 
15. Baumol, W.J. Productivity growth, convergence, and welfare: What the long-run data show. Am. Econ. Rev. 1986, 76, 1072-1085.

16. De Long, J.B. Productivity growth, convergence, and welfare: Comment. Am. Econ. Rev. 1988, 78, 1138-1154.

17. Quah, D.T. Empirical cross-section dynamics in economic growth. Eur. Econ. Rev. 1993, 37, 426-434. [CrossRef]

18. Hodrick, R.J.; Prescott, E.C. Postwar US business cycles: An empirical investigation. J. Money Credit Bank. 1997, 29, 1-16. [CrossRef]

(C) 2020 by the authors. Licensee MDPI, Basel, Switzerland. This article is an open access article distributed under the terms and conditions of the Creative Commons Attribution (CC BY) license (http://creativecommons.org/licenses/by/4.0/). 